\title{
CONTRIBUIÇÕES DO PENSAMENTO VYGOTSKIANO PARA A MODELAGEM MATEMÁTICA
}

\author{
CONTRIBUCIONES DEL PENSAMIENTO VYGOTSKIANO AL MODELAJE \\ MATEMÁTICO
}

CONTRIBUTIONS OF VYGOTSKIAN THOUGHT TO MATHEMATICAL MODELING

\author{
Ady Wallace Jaques SILVA ${ }^{1}$ \\ Roberta Modesto BRAGA ${ }^{2}$ \\ Cassio Cristiano GIORDANO ${ }^{3}$
}

RESUMO: O presente estudo é um ensaio teórico que analisa possíveis contribuições das ideias de Lev Vygotsky para o ensino de Matemática, por meio da modelagem. Para ele, o contexto histórico-cultural molda o elemento psicológico, determinando a maneira de pensar. Pessoas de diferentes culturas apresentam distintos perfis psicológicos. As funções psicológicas são desenvolvidas ao longo do tempo e mediadas pela interação social, através de símbolos culturais. A linguagem está relacionada à cultura e depende dos fatores sociais. Os conceitos são historicamente construídos e internalizados de maneira particular pelos indivíduos, de forma ampla, integrada, holística e dinâmica. Tais princípios podem contribuir para uma maior compreensão da Modelagem Matemática, uma vez que ela parte de situações apresentadas por problemas reais, alinhados às vivências dos estudantes, levando estes a assumir o protagonismo nesse processo, na medida em que desenvolvem um modelo matemático em um ambiente de aprendizagem no qual a interação se faz presente.

PALAVRAS-CHAVE: Processo histórico-cultural. Funções psicológicas. Modelagem matemática.

RESUMEN: El presente estudio es un ensayo teórico que analiza las posibles contribuciones de las ideas de Lev Vygotsky a la enseñanza de las matemáticas, a través de la modelización. Para él, el contexto histórico-cultural configura el elemento psicológico, determinando la forma de pensar. Las personas de diferentes culturas tienen diferentes perfiles psicológicos. Las funciones psicológicas se desarrollan a lo largo del tiempo y están mediadas por la interacción social, a través de símbolos culturales. El lenguaje está relacionado con la cultura y depende de factores sociales. Los conceptos son históricamente construidos e internalizados de manera particular por los individuos, de una manera amplia, integrada, holística y dinámica. Dichos principios pueden contribuir a una mayor comprensión de la modelización matemática, ya que se parte de situaciones que se presentan con problemas

\footnotetext{
${ }^{1}$ Universidade Federal do Pará (UFPA), Castanhal - PA - Brasil. Mestrado profissional em Matemática em Rede Nacional. ORCID: https://orcid.org/0000-0002-4243-1365. E-mail: adywallacejaques36@gmail.com

${ }^{2}$ Universidade Federal do Pará (UFPA), Castanhal - PA - Brasil. Professora do Instituto em Educação Matemática e Científica. Doutorado em Educação em Ciências e Matemáticas (UFPA). ORCID: https://orcid.org/0000-0003-3747-5862.E-mail: robertabraga@ufpa.br

${ }^{3}$ Faculdade Integradas de Guarulhos (FIG), São Paulo - SP - Brasil. Professor do Departamento de PósGraduação em Educação Matemática e em Psicopedagogia. Doutorado em Educação Matemática (PUC/SP). ORCID: https://orcid.org/0000-0002-2017-1195. E-mail: ccgiordano@gmail.com
} 
reales, alineados con las experiencias de los estudiantes llevándolos a asumir el protagonismo en este proceso, a medida que desarrollan un modelo matemático, en un ambiente de aprendizaje, en el que la interacción está presente.

PALABRAS CLAVE: Proceso histórico-cultural. Funciones psicológicas. Modelización matemática.

ABSTRACT: The present study is a theoretical essay that analyzes possible contributions of Lev Vygotsky's ideas to the teaching of Mathematics, through modeling. For him, the historical-cultural context shapes the psychological element, determining the way of thinking. People from different cultures have different psychological profiles. Psychological functions are developed over time and mediated by social interaction, through cultural symbols. Language is related to culture and depends on social factors. Concepts are historically constructed and internalized in a particular way by individuals, in a broad, integrated, holistic and dynamic way. Such principles can contribute to a greater understanding of Mathematical Modeling, since it starts from situations presented with real problems, aligned with the students' experiences leading them to assume the protagonism in this process, as they develop a mathematical model, in an environment of learning in which the interaction is present.

KEYWORDS: Historical-cultural process. Psychological functions. Mathematical modeling.

\section{Introdução}

O ensino de Matemática no Brasil tem enfrentado muitos desafios nas últimas décadas, tanto no que diz respeito aos processos de ensino e de aprendizagem em si, quanto na forma como a disciplina é vista pela sociedade, de modo geral. Quando um professor, ao se deparar com quarenta estudantes em uma sala de aula, lança a seguinte pergunta: "Qual a disciplina que vocês mais gostam?", de acordo com a nossa experiência docente, sobretudo nos anos finais do Ensino Fundamental e no Ensino Médio, a Matemática raramente é mencionada. Neste trabalho, tecemos algumas considerações sobre alguns conceitos centrais na obra do psicólogo russo Lev Semionovich Vygotsky, com o intuito de auxiliar os professores que ensinam Matemática a desenvolver estratégias docentes envolvendo a modelagem.

Segundo Vygotsky (1996; 2000; 2001), é o aprendizado coletivo que irá promover o desenvolvimento humano, uma vez que o homem é um ser social, fruto de um agregado de interações sociais e históricas. A relação do homem com o mundo não é direta, mas sim mediada por instrumentos e signos. O autor ressalta a importância do pensamento e da linguagem (se referindo especialmente à fala, ao discurso) nessa relação. Destaca ainda, em sua obra, os conceitos espontâneos e científicos; o chamado método inverso; o nível de 
desenvolvimento atual (real), de desenvolvimento potencial e de desenvolvimento próximo, ou zona de desenvolvimento proximal.

Em nossa análise, adotaremos como referencial teórico algumas ideias de Vygotsky, na perspectiva da Psicologia Marxista, bem como grandes referências no campo Modelagem Matemática, tais como: Bassanezi (1999), Burak (1999), Biembengut (2000), e Barbosa (2004). Consideramos, à luz desses referenciais teóricos, a Modelagem Matemática como estratégia de ensino viável, quer seja na Educação Básica, como aliás está previsto na Base Nacional Comum Curricular - BNCC (BRASIL, 2018), quer seja na Educação Superior.

Nos valemos das ideias de Vygotsky, na tentativa de mudar a percepção descontextualizada e negativa da Matemática manifestada por grande parte dos estudantes. Consideramos essa mudança essencial para o sucesso das práticas educativas nessa disciplina, uma vez que ele é o sujeito principal na apropriação do saber nos processos de ensino e de aprendizagem, levando em conta seu contexto histórico-cultural, por meio de sua interação com os pares. Ressaltamos, ainda, um ponto basilar: como tem sido abordados os problemas matemáticos? Estes estão de acordo com a realidade destes estudantes, ponto chave para uma aprendizagem significativa, contribuindo para a formação de sujeitos autônomos e críticos, na perspectiva de Skovsmose $(2014 ; 2018)$ ?

\section{Algumas concepções de Vygotsky}

Apresentaremos, a priori, alguns conceitos deste psicólogo que tem suas raízes inspiradas em Karl Marx, mais precisamente no materialismo histórico-dialético, um dos principais métodos de análise sociológica a respeito da luta de classes sociais. Vygotsky (1987; 1996) ressalta o papel da cultura no processo de cognição, já que esta não é vista como algo estático, pelo contrário, ela passa por um processo de transformação e vai trazer como conceito básico a respeito de seu pensamento, o que ele denomina de dialética. Isto é, a forma como o homem age sobre e com o mundo, produzindo assim a cultura, e essa cultura, agindo sobre e com o homem, transformando-o. Esse autor criou o conceito de mediação, assim descrita como uma experiência social que requer participação e colaboração, tanto dos estudantes quanto dos professores.

Em se tratando de desenvolvimento e aprendizagem, diferente da ideia de Piaget, cujo foco da obra recai sobre o processo de desenvolvimento individual como gerador de condições para aprendizagem (LA TAILLE; OLIVEIRA; DANTAS, 2019), Vygotsky parte do pressuposto de que a aprendizagem gera o desenvolvimento e não o contrário. Devemos 
frisar aqui que esse autor não nega as condições biológicas como muito se tem pensado, apenas não se baseia numa perspectiva biológica para reconhecer o papel da criança no mundo.

Vygotsky (2010) dá ênfase às chamadas funções psicológicas superiores ou especificamente humanas, as quais são mediadas pela cultura. O homem não é o mesmo sempre, este vai mudando, se transformando ao longo de todo o processo histórico. Para compreender a relação entre desenvolvimento e aprendizagem, é necessária a compreensão do que chamamos de nível de desenvolvimento atual ou real, isto é, aquilo que a criança consegue realizar sozinha, que caracteriza o desenvolvimento mental retrospectivamente, as funções já amadurecidas; bem como de zona de desenvolvimento proximal, caracterizado pelo desenvolvimento mental prospectivamente, as abstrações, as funções que ainda não amadureceram. Ainda neste nível, a criança consegue realizar uma tarefa com a ajuda de um adulto ou em cooperação com outros que já compreenderam tal problema, como ilustrado na figura abaixo:

Figura 1 - Relação entre as zonas de desenvolvimento real, proximal e potencial

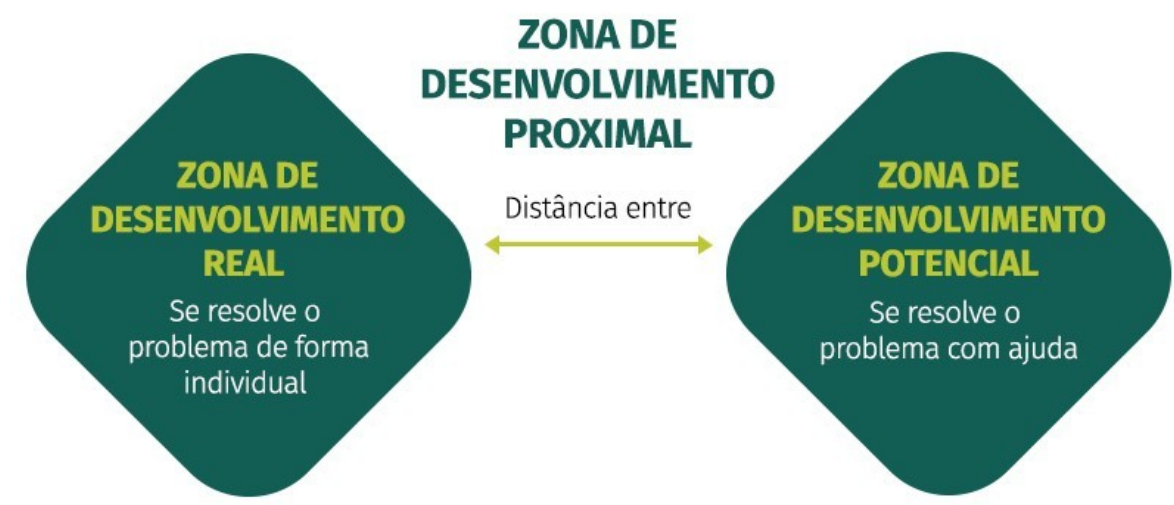

Fonte: Brasil (s/a)

Em relação à mediação, Vygotsky $(2000 ; 2010)$ destaca dois elementos mediadores que são os instrumentos e os signos, elos a mais nessa relação de desenvolvimento e troca que se dão entre o indivíduo e o meio no qual estão inseridos.

Nos signos, por exemplo, está a capacidade de representar o mundo, são as representações mentais que substituem o objeto ausente, por exemplo: a linguagem, a produção científica, a construção de ideias e conceitos. Esse autor rompe com a ideia da relação estímulo-resposta. Para ele, entre esses dois fatores há um processo de mediação que irá atuar no pensamento da criança levando então a uma resposta. A partir dessa mediação é 
que devemos refletir em relação aos processos educacionais no que diz respeito ao papel do docente e dos sujeitos que estão presentes no convívio da criança, método este chamado de dupla estimulação.

No que diz respeito ao pensamento e linguagem, Vygotsky $(1987 ; 2000)$ trabalha com o pressuposto de que a língua é um objeto de estudo primordial. Ele trabalha com duas funções da linguagem, que são: a comunicação, em que as pessoas desenvolvem a língua para se comunicar, isto é, a linguagem nasce como forma de comunicação; e o pensamento generalizante, que é onde a língua se encaixa com o pensamento. É nesta segunda função que a relação pensamento e linguagem se torna forte. $\mathrm{O}$ uso da linguagem implica em uma compreensão generalizada do mundo. O psicólogo ainda afirma que o primeiro uso da linguagem é o que ele denomina de fala socializada, que é a fala da criança com os outros e para os outros, e destaca também o chamado discurso interior, isto é, a fala para mim.

Em se tratando do estudo a respeito da formação de conceitos, Vygotsky (1987; 1996; 2000), diferencia os conceitos espontâneos e os conceitos científicos. O primeiro se identifica como não conscientizado sobre o ato de pensar, a atenção está sempre relacionada ao objeto, isto é, ao concreto. O segundo conceito refere-se à conscientização, porém, para o psicólogo, essa conscientização só ocorre caso a criança for capaz de explicar como faz algo.

Não podemos pensar no desenvolvimento dos conceitos sem levar em conta o contexto em que vivemos, pois seria uma forma de pensamento sem vida e sem os aspectos históricos, sociais e culturais que constituem tais processos na relação individual e coletiva do sujeito.

\section{Algumas concepções sobre a Modelagem Matemática}

Nessa seção apresentamos o conceito de Modelagem Matemática na perspectiva de algumas das principais referências nacionais, por se tratar de uma das metodologias ativas preconizadas pela BNCC (BRASIL, 2018), alternativa mais dinâmica, que coloca os estudantes como protagonistas no processo de apropriação do conhecimento.

A modelagem está presente em nossa civilização desde os primórdios, é considerada tão antiga quanto a própria Matemática. Iniciamos nossa reflexão com o conceito de Modelagem Matemática ancorados em Bassanezi (2011), que a emprega no sentido de transformar problemas da realidade em problemas matemáticos e resolvê-los interpretando suas soluções na linguagem do mundo real.

A Modelagem Matemática de uma situação ou problema apresentado aos estudantes apresenta uma sequência de etapas que serão visualizadas no esquema da figura abaixo: 
Figura 2 - Etapas da Modelagem Matemática propostas por Bassanezi

Fonte: Bassanezi (2011, p. 27)

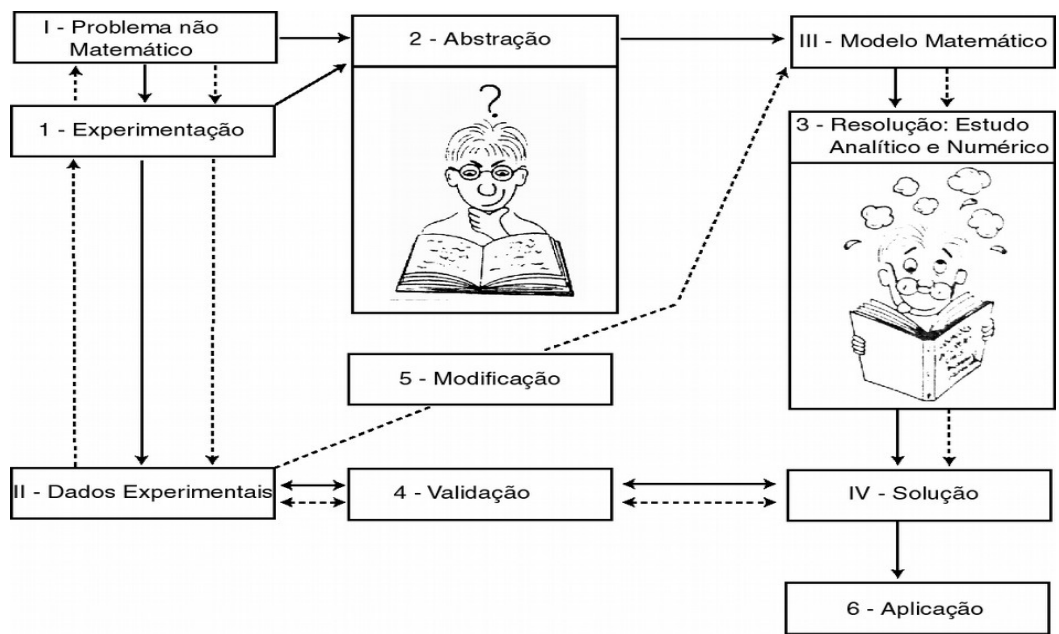

As etapas propostas por Bassanezi (2011) são: a experimentação, abstração, resolução, validação e modificação, as quais irão auxiliar os estudantes no processo de ensino e aprendizagem, auxiliando também a prática docente.

De acordo com Bassanezi (1999), a Modelagem consiste em processo de elaboração de modelos realistas definido por estratégias de ação de cada indivíduo sobre uma dada realidade, impregnada das interpretações e intersubjetividades peculiares de cada modelador.

Prosseguiremos com Biembengut (1999). Em sua visão, a Modelagem Matemática é um meio no qual dois conjuntos disjuntos interagem: a Matemática e a realidade. É o processo que envolve a obtenção de um modelo, despertando assim, nos discentes, o interesse em aprender conteúdos de matemática que antes eles não conheciam. 
Figura 3 - Processo de Obtenção de um Modelo.

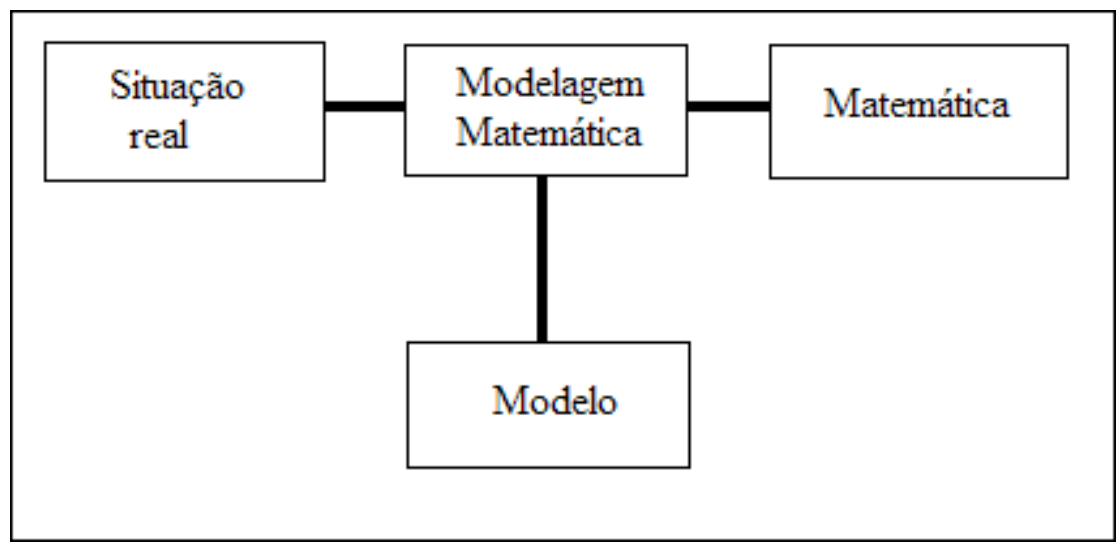

Fonte: Adaptado de Biembengut (1999)

Biembengut (1999) divide esses procedimentos em três etapas, chamadas pela autora de interação com o assunto, a matematização e, por último, o chamado Modelo Matemático. Essas três etapas serão subdivididas em seis subetapas que veremos na sequência.

Nessa abordagem, se faz necessário o reconhecimento da situação-problema e a familiarização com o assunto a ser modelado. Nesta primeira etapa, é definido o assunto que será estudado. Na segunda etapa, a matematização é constituída das subetapas formulação do problema (as hipóteses) e a resolução do problema exposto. É uma fase que irá desafiar o estudante. A criatividade e as experiências que os discentes trazem de suas vidas são de suma importância nessa tradução do problema real para a linguagem matemática. A terceira e última etapa, denominada de Modelo Matemático, tem como subetapas a interpretação da solução e a validação dela, já que se faz necessário verificar se a solução encontrada satisfaz as condições do problema exposto, caso não, o processo deve retornar à segunda etapa, sendo reorganizada.

Dionísio Burak (2004) compreende a Modelagem Matemática como uma metodologia alternativa para o ensino de Matemática, centrada no interesse dos envolvidos no processo. Ademais, Burak (2004) aponta como sugestão que as atividades de modelagem sejam realizadas considerando cinco etapas diferentes: escolha do tema; pesquisa exploratória; levantamento dos problemas; resolução do(s) problema(s) e o desenvolvimento da Matemática relacionada ao tema; análise crítica da(s) solução (es). O autor diz que:

A Modelagem Matemática constitui-se em um conjunto de procedimentos cujo objetivo é construir um paralelo para tentar explicar, matematicamente, os fenômenos presentes no cotidiano do ser humano, ajudando-o a fazer predições e a tomar suas decisões (BURAK, 1992, p. 62). 
Barbosa (2004) e Barbosa, Caldeira e Araújo (2007), sublinham que a Modelagem Matemática está no sentido de ser um ambiente de aprendizagem em que os estudantes serão convidados a investigar e a problematizar por meio da Matemática as situações da realidade. Para estes autores, uma atuação para ser chamada de Modelagem Matemática precisa basicamente apresentar duas características: a primeira é ser um problema realista, de grande interesse para os estudantes, sobre o qual os discentes não tenham nenhum esquema prévio para resolução, precisando elaborá-lo no processo da própria modelagem; a segunda é que tal problema seja externo à matemática, isto é, a modelagem se debruce sobre problemas que sejam a priori externos a essa disciplina.

Um dos pontos a destacar sobre a modelagem é que os estudantes não irão apenas resolver os problemas propostos, mas sim, irão participar da elaboração dos/nos e pelos processos de aprendizagem, levando o alunado a um maior interesse pela disciplina, mais do que isso, mostrando também o papel da Matemática na sociedade.

Barbosa (2004, p. 04) acrescenta que: "Os alunos têm um pouco mais de participação, pois, trazem o problema e integram-se em todas as etapas para resolver o problema, isto é, buscam informações que possibilitem a criação do modelo bem como a validação deste".

Concordamos com o autor, pois o processo de Modelagem Matemática só é possível se existe o engajamento do aluno. É um trabalho autoral, que contempla o que prescreve a BNCC (BRASIL, 2018), no sentido da promoção do protagonismo discente por meio de metodologias ativas de ensino.

\section{Possíveis contribuições do pensamento Vygotskiano para a Modelagem Matemática}

Nesta terceira seção, buscamos articular os conceitos já apresentados do pensamento vygotskiano com a Modelagem Matemática, enquanto proposta alternativa tanto para o planejamento docente quanto para as práticas em sala de aula.

O professor que ensina Matemática precisa considerar o pressuposto de que o estudante é fruto do contexto histórico-cultural em relação ao meio em que vive. Assim, não podemos compreender que todos os discentes aprendem do mesmo jeito e no mesmo ritmo (BRASIL, 2018). A cultura e a socialização desempenham um papel crucial em seu desenvolvimento pois, para Vygotsky, só há aprendizagem a partir do outro. Na ausência do outro, o homem não se constrói homem. Nessa perspectiva, a formação se dá na relação entre o sujeito e a sociedade a seu redor. Dessa forma, o indivíduo modifica o ambiente e este o modifica de volta. 
Em nossa experiência docente, observamos que, quando ministramos aulas de Matemática por meio da Modelagem Matemática na Educação Infantil e anos iniciais do Ensino Fundamental, as crianças apresentam os conceitos espontâneos, nos quais elas não estão plenamente conscientes de seus pensamentos, o seu olhar está voltado para o objeto, daí a importância de se trabalhar com o concreto, no caso da contagem e as operações matemáticas.

Para os estudantes do Ensino Fundamental (anos finais), Ensino Médio e Superior, podemos enfatizar os conceitos científicos, pois já apresentam maturidade e nível de conhecimento necessário para uma compreensão mais aprofundada acerca dos conceitos matemáticos que serão trabalhados nas atividades de modelagem, por exemplo, o conceito de função afim. Daí a importância de o docente realizar atividades nas quais o estudante não apenas apresente a resposta, mas consiga, de forma consciente e crítica, justificá-la.

Quando um professor faz uso da Modelagem Matemática, seja qual for o nível de ensino, está contribuindo para que os estudantes percebam que a disciplina Matemática pode fazer sentido na vida deles, tornando-os mais críticos e instigando-os pela busca do conhecimento científico.

Vygostky (1987; 2000; 2010), no que diz respeito ao pensamento e linguagem, pode oferecer importantes contribuições para a Modelagem Matemática, no sentido de que quando o estudante está resolvendo um problema, preferencialmente de forma colaborativa, em pequenos grupos, a comunicação entre os pares é essencial. $\mathrm{O}$ uso da linguagem materna e da linguagem matemática se faz presente em suas interações sociais na atividade didática, como defende Machado (1994), fazendo com que esse estudante desenvolva competências (BRASIL, 2018) que lhe confiram domínio seguro sobre o conteúdo matemático sobre o qual está interagindo com colegas e com o próprio professor.

O processo de aprendizagem matemática, por meio da modelagem, deve ser mediado, seja pelo professor ou até pelos colegas de classe que já tenham amadurecido ou aprendido tais conceitos matemáticos. Em suma, a partir dos conceitos matemáticos que já foram amadurecidos (zona de desenvolvimento real) podemos, na/pela mediação, contribuir para potencializar o nível de desenvolvimento próximo, isto é, os que ainda não amadureceram.

Vygotsky (1987; 1996), influenciado pelo pensamento marxista, sobretudo quanto ao materialismo histórico e dialético, o define como sendo um método de interpretação da realidade, uma realidade intrinsecamente dinâmica e contraditória, se alimentando dialeticamente de novas descobertas e de novos questionamentos. Por meio desses novos questionamentos, novas saberes são construídos individual e coletivamente. 
Esse método subentende que a nossa realidade objetiva é histórica, diacrônica, acompanhada atenta e participativamente ao longo da história. Isso permite que possamos analisar a nossa realidade como um processo em desenvolvimento. Por isso é necessário compreender nossas vivências em uma sociedade que aliena e que é alienada a fim de desconstruí-la com e pelo pensamento crítico.

Os estudantes precisam ter consciência da sociedade em que vivem e do modelo capitalista no qual estão inseridos e, principalmente, que com o passar do tempo eles não serão mais os mesmos, estarão em processo de constante mudança, por se considerar sua constituição enquanto sujeito inacabada, inconclusa. Nesse contexto, questionamos: qual a contribuição dessas ideias para a Modelagem Matemática?

É necessário que os próprios docentes se apropriem desses estudos e ousem, municiados e constituídos nos/pelos e com os recursos das metodologias ativas propostas na BNCC (BRASIL, 2018). D’Ambrosio (2012, p. 95) assevera que:

Ao começar a aula, o professor tem uma grande liberdade de ação. Dizer que não dá para fazer isso ou aquilo é desculpa. Muitas vezes é difícil fazer o que se pretende, mas cair numa rotina é desgastante para o professor. [...] Nenhum profissional deve fazer a mesma coisa por mais de quatro ou cinco anos. A aparente aquisição de uma rotina de execução conduz à falta de criatividade e consequentemente à ineficiência, mas o que é mais grave é o estresse [...]. A Organização Internacional do Trabalho indica ser o magistério uma das profissões mais estressantes.

Os problemas matemáticos realistas, contextualizados no universo de interesses dos estudantes, alinhados às necessidades da comunidade local, com o auxílio da modelagem, permitem o desenvolvimento da materacia ${ }^{4}$ (D’AMBROSIO, 2012; SKOVSMOSE, 2014).

O objetivo maior dos processos de ensino e aprendizagem é propiciar condições para o desenvolvimento de cidadãos conhecedores da sua história, que refletem criticamente (SKOVSMOSE, 2014; 2018) e são capazes de lutar pela construção de uma sociedade melhor.

\section{Considerações finais}

Procuramos refletir como as ideias de Vygotsky podem contribuir sobremaneira para auxiliar as práticas dos professores no âmbito da Modelagem Matemática, psicólogo este influenciado pelas ideias de Marx, em relação ao materialismo histórico e dialético,

\footnotetext{
${ }^{4}$ D'Ambrosio entende materacia como a capacidade de interpretar e manejar sinais e códigos e de propor e
} utilizar modelos na vida cotidiana. 
evidenciando sua importância para a educação matemática crítica. Apresentarmos aos estudantes uma Matemática viva, dinâmica, centrada em sua realidade, de forma significativa para eles, ou seja, que na e pela relação com ela e com o outro possam produzir sentidos na escola e em outros espaços sociais.

Pretendemos, assim, contribuir para o desenvolvimento de estudantes autônomos, capazes de pensar, de refletir, de conhecer sua história e o contexto em que vivem e discutir sobre e com ele, capazes de lutar por equidade na sociedade capitalista à qual estão inseridos e que ainda vislumbrar a igualdade social.

Docentes e discentes precisam trabalhar de modo colaborativo. Esperamos que este trabalho auxilie os professores que ensinam Matemática, enquanto planejamento em todos os níveis de ensino, para uma formação da cidadania. Quando um professor conhece a realidade de seu estudante, os processos de ensino e de aprendizagem fluem de maneira mais construtiva, pois o discente sente-se à vontade para compartilhar suas dúvidas, suas emoções, suas conquistas, seus anseios e até mesmo seus temores, o que se mostra de extrema importância no contexto atual vivenciado no mundo pela pandemia da COVID-19.

O educador e o educando precisam reconhecer e assumir seus papéis na sociedade, compreendendo a relevância do ensino e da aprendizagem matemática nesse empoderamento. Acreditamos, assim, contribuir para uma melhor aceitação da Matemática em suas vidas, pontualmente, pela compreensão de sua importância na escola e em outros contextos históricos e sociais.

\section{REFERÊNCIAS}

BARBOSA, J. C. Modelagem Matemática na sala de aula. In: ENCONTRO NACIONAL DE EDUCAÇÃO MATEMÁTICA, 8., 2004, Recife. Anais [...]. Recife, PE: Universidade Federal de Pernambuco, 2004.

BARBOSA, J. C.; CALDEIRA,

BASSANEZI, R. C. Ensino-aprendizagem com modelagem matemática: uma nova estratégia. São Paulo, SP: Contexto, 2011.

BASSANEZI, R. C. Modelagem Matemática: uma disciplina emergente nos programas de formação de professores. Uma disciplina emergente nos programas de formação de professores. 1999. Disponível em: http://www.ime.unicamp.br/ biomat/bio9art_1.pdf. Acesso em: 01 dez. 2020.

BIEMBENGUT, M. S. Modelagem matemática \& implicações no ensino e aprendizagem de matemática. Blumenau: FURB, 1999. 
BIEMBENGUT, M. S.; HEIN, N. Modelagem matemática no ensino. São Paulo, SP: Contexto, 2000.

BRASIL. Ministério da Educação. Base Nacional Comum Curricular: Educação é a Base. Brasília, DF: MEC, 2018.

BRASIL. Ministério da Educação. O uso de metodologias ativas colaborativas e a formação de competências. Aprofundamentos. Brasília, DF: MEC, s/a. Disponível em: http://basenacionalcomum.mec.gov.br/implementacao/praticas/caderno-de-praticas/ aprofundamentos. Acesso em: 10 set. 2020.

BURAK, D. Modelagem Matemática sob um olhar de Educação Matemática e suas implicações para a construção do conhecimento matemático em sala de aula. Revista de Modelagem na Educação Matemática, Blumenau (SC), v. 1, n. 1, p. 10-27, 2010. D'AMBROSIO, Ub. Educação Matemática: da teoria à prática. Campinas, SP: Papirus Editora, 2012.

LA TAILlE, Y.; OLIVEIRA, M. K.; DANTAS, H. L. Piaget, Vygotsky, Wallon: teorias psicogenéticas em discussão. São Paulo, SP: Summus Editorial, 2019.

MACHADO, N. J. Matemática e Língua Materna: análise de uma impregnação mútua. São Paulo, SP: Cortez Editora, 1994.

SKOVSMOSE, O. interpretações de significado em educação matemática. Bolema, Rio Claro (SP), v. 32, n. 62, p. 764-780, 2018. DOI: doi.org/10.1590/1980-4415v32n62a01

SKOVSMOSE, O. Um convite à educação matemática crítica. Campinas, SP: Editora Papirus, 2014.

VYGOTSKY, L. S. A construção do pensamento e da linguagem. São Paulo, SP: Martins Fontes, 2000.

VYGOTSKY, L. S. Aprendizagem e desenvolvimento intelectual na idade escolar. In: VYGOTSKY, L. S.; LURIA, A. R.; LEONTIEV, A. N. Linguagem, desenvolvimento e aprendizagem. São Paulo, SP: Ícone, 2010, p. 103-117.

VYGOTSKY, L. S. O significado histórico da crise da psicologia: uma investigação metodológica. In: VYGOTSKY, L. S. Teoria e método em psicologia. Trad. Claudia Berliner. São Paulo, SP: Martins Fontes, 1996. p. 203-417.

VYGOTSKY, L. S. Vygotsky: contexto, contribuições à psicologia e o conceito de zona de desenvolvimento proximal. Itajaí, SC: Univali, 2001.

VYGOTSKY, L. S. Pensamento e linguagem. São Paulo, SP: Martins Fontes, 1987. 


\section{Como referenciar este artigo}

SILVA, A. W. J.; BRAGA, R. M.; GIORDANO, C. C. Contribuições do pensamento vygotskiano para a modelagem matemática. Revista Ibero-Americana de Estudos em Educação, Araraquara, v. 16, n. esp. 3, p. 1681-1693, jun. 2021. e-ISSN: 1982-5587. DOI: https://doi.org/10.21723/riaee.v16iesp.3.15305

Submissão em: 05/02/2021

Revisões requeridas em: 30/03/2021

Aprovado em: 12/05/2021

Publicado em: 01/06/2021 